\title{
Effect of Nordic Hamstring Curl Exercise to Prevent Hamstring Injury in Sprinters
}

\author{
Kashyap Patel ${ }^{1}$, Karishma Barot ${ }^{2}$ \\ ${ }^{1}$ BPT Intern, ${ }^{2}$ Tutor, \\ Nootan College of Physiotherapy, Sankalchand Patel University, Visnagar, Gujarat, India 384315 \\ Corresponding Author: Kashyap Patel
}

DOI: https://doi.org/10.52403/ijrr.20220303

\begin{abstract}
Background: Hamstring strain injuries comprise a substantial percentage of acute musculoskeletal injuries. Nordic hamstring curl may effective in reducing the risk of Hamstring Strain Injury. High-speed running is generally occurring of hamstring strain injuries. FASH may help in prevention of hamstring injury

Aim: The aim of the study is to find out the effect of Nordic hamstring curl exercise in Sprinters, as these are the muscles mainly getting affected and resulting in improper movements and gait pattern.

Objective: To improve the functional activities of the participant. And to find out the effect of Nordic hamstring curl exercise in Sprinters.

To increase the functional measures of the participants

Method: In a 10 week intervention study 30 participants with hamstring injury were studied they were participated in a group by convenience sampling, pre and post data was collected and analyzed using SPSS 22.0 paired t-test were used to find out the significance of the treatment.
\end{abstract}

Results: A significant prevention in injury $(\mathrm{p}<0.05)$ after the treatment was found.

Conclusions: The study concluded that effect of Nordic hamstring curl exercise is more effective to prevent hamstring injury in sprinters.

Keywords: Sprinters, Hamstring injury, FASH, NHC, gait

\section{INTRODUCTION}

Hamstring strain injuries comprise a substantial percentage of acute musculoskeletal injuries incurred during sporting activities at the high school, collegiate, and profession levels. ${ }^{(1,2,3,4)}$ Participants in track, football, and rugby are especially prone to this injury given the sprinting demands of these sports, ${ }^{(5,6,7)}$ while dancers have a similar susceptibility due, in part, to the extreme stretch incurred by the hamstring muscles ${ }^{(8)}$.

The occurrence of hamstring strain injuries during high-speed running is generally believed to occur during terminal swing phase of the gait cycle, ${ }^{(9)}$ a perception supported by the objective findings of 2 separate hamstring injury cases. ${ }^{(10,11)}$

Strains usually occur in the biceps femoris, ${ }^{(26,27)}$ and the most common location is near the muscle-tendon junction. ${ }^{(26,28)}$

Most studies suggest that hamstring strains occur during the later part of the swing phase when the hamstrings are working to decelerate knee extension that is, the muscle develops tension while lengthening and absorbing energy from the decelerating limb in preparation for foot contact. $^{(12,13,14)}$

During the second half of swing, the hamstrings are active, lengthening Such movements place the hamstrings in a position of extreme stretch, with injuries most commonly presenting in the semimembranosus and its proximal free tendon (as opposed to the intramuscular tendon).Suggested modifiable risk factors include hamstring weakness, fatigue, and lack of flexibility, ${ }^{(15,16,17,18)}$ with a strength imbalance between the hamstrings 
(eccentric) and quadriceps (concentric) being most supported by evidence. ${ }^{(19,20,21)}$

The hamstrings, including

inadequate flexibility of the muscles, (2) inadequate muscle strength and/or endurance,(3) dyssynergic muscle contraction,(4) insufficient warm-up and stretching before activity, (5) an awkward running style, and (6) a return to activity before complete rehabilitation. ${ }^{(29)}$

Grade I injuries are mild with no loss of strength or function, minimal loss of musculotendinous unit structural integrity, and low-grade inflammation. Grade II injuries include partial or incomplete tears and present with moderate loss of strength. There may be muscular edema and hematoma locally. Grade III injuries are severe, involve complete tears or rupture and result in significant loss of function. $(30,31,32)$

Type II hamstring strains occur in the setting of excessive lengthening of the hamstrings. (33) These types of hamstring strains are more common in activities such as dancing, slide tackling and high kicking that combine hip flexion with knee extension. ${ }^{34,35)}$ common in activities such as dancing, slide tackling and high kicking that combine hip flexion with knee extension. ${ }^{(34,35)}$

The popularity of the NHE(Nordic Hamstring Exercise) may lie in its ease of use, requiring no equipment and being effective at reducing the risk of HSI (Hamstring Strain Injury). ${ }^{(22)}$ While the NHE is an effective prevention tool, we continue to observe a high incidence of HSI.

A greater appreciation for the multi factorial nature of HSI while also addressing the primary injury mechanism- sprinting (23) is required. The NHE is only one method of strengthening, which is important for hamstring health. While the exercises discussed develop eccentric hamstring strength, the contractions occur at a much slower rate than during sprinting and it would be logical to regularly and progressively expose the athlete to highspeed running. The need of the study was to find the effect of Nordic hamstring curl exercise to prevent Hamstring Injury in Sprinter.

\section{AIM AND OBJECTIVE}

Aim: The aim of the study is to find out the effect of Nordic hamstring curl exercise in Sprinters, as these are the muscles mainly getting affected and resulting in improper movements and gait pattern.

Objective: The main objective is to improve the functional activities of the participant. To find out the effect of Nordic hamstring curl exercise in Sprinters. To increase the functional measures of the participants.

\section{HYPOTHESIS \\ NULL HYPOTHESIS}

[H0]-.There is no effect on sprinters to prevent hamstring injury using Nordic hamstring curl exercise

\section{ALTERNATIVE HYPOTHESIS}

[H1]-.There is effect on sprinters to prevent hamstring injury using Nordic hamstring curl exercise

\section{METHODOLOGY Method}

- Research design- An Experimental study

- Study setting-Nootan College of Physiotherapy, Sports OPD.

- Sample design: Convenience Sampling

- Study population- 18 to 25 year $\{$ male $\}$

- Study sample- 30

- Study duration- 10 weeks

Criteria for Selection

Inclusion Criteria

- Age - 18 to 25 years

- Gender- Male

- BMI - 18.5-24.9

- Grade II Hamstring injury

- Pain with resisted knee flexion

- Pain with resisted hip extension

- Pain with passive hip flexion with the knee extended

- Provocation of pain on isometric contraction of posterior thigh muscles

Exclusion Criteria

- Uncertain clinical diagnosis 
- Verified or previously suspected posterior thigh muscle injury

- Recent Fractures and Extrinsic trauma to the posterior thigh

- Chronic Low Back Pain and/or sciatica

\section{Outcome measure}

- FASH:-Functional assessment scale for hamstring ${ }^{(24)}$

\section{Procedures of Data Collection}

The research was approved by the ethics committee of Nootan College of Physiotherapy, SK University, Visnagar. The Nordic hamstring exercise will be first and foremost demonstrated to the participant. All the participants will be known and will be willingly signing inform written consent form. The participant's position will be kneeling on mat and the participant will be made to relax. The NHC with warm up and cool down treatment will be given. Treatment will be given in different sessions for 10 weeks per week there is one session will be performed by the participant, 2 sets and 5 repetition for each and then further it will be proceed for progression in sessions and repetitions of sets. Pre and post treatment data will be taken and statistical analysis will also be performed and mentioned. The warm up and cool down will mainly include raising your

body temperature and increasing as well regulates blood flow to muscles.

1. Treatment Protocol

Warm up

- A skip x 30 Second

- B skip x 30 Second

- Toe walking x 30 Second

- Walk on heel x 30 Second

- Sideways jumping Jack's x 30 Second

- Butt kicks x 30 Second

- Neck rolls x 30 Second

- Arm circle x 30 Second

- Torso rotation x 30 Second

- Knee rotation x 30 Second

- Side to side leg swing x 60 Second(B/L)

- Front to back leg swing x 30 Second

- Nordic hamstring curl Exercise

$\circ$ The athlete is kneeling on the ground with ankles stabilized therapist hands.

o The athlete is then instructed to fall forward, and resist the fall to the ground for as long as possible using his hamstring muscle.

Table: 1 Training Protocol for Nordic Hamstring Exercise

\begin{tabular}{|c|c|c|}
\hline Week & Session per week & Sets and repetitions \\
\hline 1 & 1 & $2 \times 5$ \\
\hline 2 & 2 & $2 \times 6$ \\
\hline 3 & 3 & $3 \times 6-8$ \\
\hline 4 & 3 & $3 \times 8-10$ \\
\hline $5-10$ & 3 & 3 sets, $12-10-8$ reps \\
\hline $10+$ & 1 & sets, $12-10-8$ reps \\
\hline
\end{tabular}

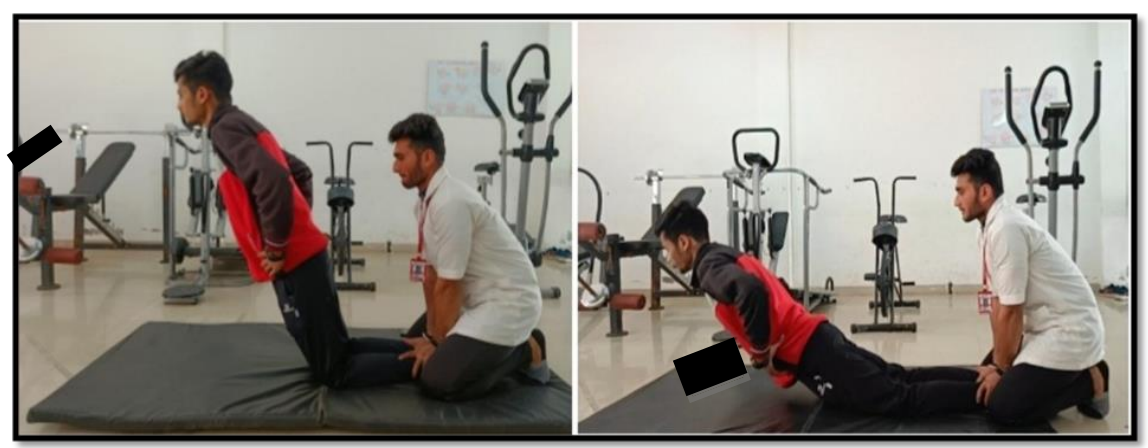

Figure 1: Nordic Hamstring Curl Exercise

Cool down:- 15 Minute

- Calf stretch 3 Rep x 30 sec Hold

- Hamstring stretch 3 Rep x 30 sec Hold

- Inner thigh stretch 3 Rep x 30 sec Hold

- Glutei stretch 3 Rep x 30 sec Hold

- Knee to chest stretch 3 Rep B/L

- Child pose with reaches 3 Rep x $30 \mathrm{sec}$ Hold
- Butterfly 15-20 Rep

\section{RESULT}

\begin{tabular}{|c|c|c|}
\hline \multicolumn{3}{|c|}{ Demographic Details } \\
\hline & MEAN & 21.83 \\
\hline Age & SD & 2.03 \\
\hline
\end{tabular}

Table 3 and Graph 1 shows intergroup comparison of pre and post treatment FASH 
Score in Group A, where the $\mathrm{p}$ value is $<0.05$. A statistically significant difference was found between the pre and post treatment FASH Score, with a significant reduction in FASH score after treatment.

Table 3: Intergroup comparison of pre and post treatment FASH Score

\begin{tabular}{|c|c|c|c|c|c|c|}
\hline \multirow{2}{*}{ Outcome } & \multicolumn{2}{|c|}{ Pre-Treatment } & \multicolumn{2}{|c|}{ Post-Treatment } & \multirow{2}{*}{ t value } & \multirow{2}{*}{ p value } \\
\cline { 2 - 5 } & Mean & SD & Mean & SD & & \\
\hline FASH Score & 0.6530 & \pm 0.034 & 0.7903 & \pm 0.029 & -29.873 & 0.00 \\
\hline
\end{tabular}

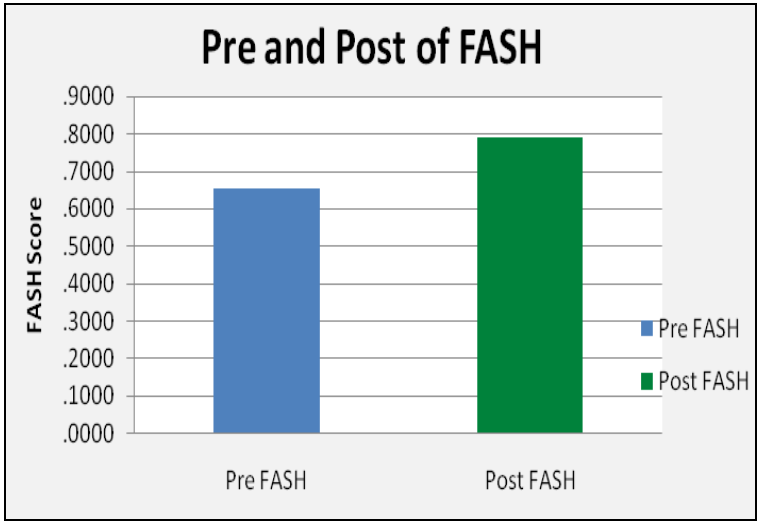

Graph 1: Intergroup comparison of pre and post treatment FASH Score

\section{DISCUSSION}

The aim of the study is to find out the effect of Nordic hamstring curl exercise in Sprinters, as these are the muscles mainly getting affected and resulting in improper movements and gait pattern.

The results found in this study disclosed that after a ten-week treatment program, thirty participants, who received Nordic curl exercises program significant improvement in the strength and reduced pain and prevent injury.

Hamstring strain injuries comprise a substantial percentage of acute musculoskeletal injuries incurred during sporting activities at the high school, collegiate, and profession levels..$^{(1,2,3,4)}$ Participants in track, football, and rugby are especially prone to this injury given the sprinting demands of these sports, ${ }^{(5,6,7)}$ while dancers have a similar susceptibility due, in part, to the extreme stretch incurred by the hamstring muscles. ${ }^{(8)}$

Nordic curl exercise is one of the most important components of rehabilitation programmes for patients with hamstring injury. The Nordic curl exercise program provided strengthening of hamstring muscle and prevents injury.
A study conducted by Minara Akter, et.al(2020), Studied that Causes and Management of Hamstring Strain of Athletes in Bangladesh They have concluded that Nordic hamstring exercises may decrease the incidence of acute hamstring injuries and also with Strengthening program for strength imbalance athlete can prevent the risk of hamstring injury.

A study reported by Emma Sconce, et.al. (2015) conducted study on The Validity of the Nordic Hamstring Lower for a Field-Based Assessment of Eccentric Hamstring Strength. They have concluded that the break-point angle achieved during Nordic hamstring lowers could be used as a field-based assessment of eccentric hamstring strength.

This study was conducted on thirty subjects with mean age of $21.83 \pm 2.036$ (mean \pm SD). The participants were received Nordic Curl Exercise Program for 10 weeks. In this study functional assessment scale for hamstring were used as outcome measures. The results showed a significant improvement in the outcome measures in post-treatment stage as compared to the pretreatment stage.

Though a significant improvement was found after treatment in group ( $\mathrm{P}$ value $<0.05$ )

Thus, the fail to accept null hypothesis [H0]

The above exposed statement suggests that Nordic hamstring curl exercise in the effective management of subjects with hamstring injury in improving hamstring muscle strength and endurance, reduction of pain and preventing hamstring injuries. 


\section{CONCLUSION}

Present study showed significant improvement in reduction of pain and prevent grade II hamstring injury in sprinters. The use of Nordic hamstring curl exercise shows a significantly greater improvement in reduction of pain and preventing hamstring injuries.

\section{Limitations of the study}

- Small sample size

- The study Involved sprinters only

Future recommendations of the study

- Carry out the study with a large sample size

- Same protocol use for other radiculopathies

\section{Acknowledgement}

First, I would like to thank my parents Mrs. Nitaben Patel and Mr. Hasmukhbhai Patel for their valuable support throughout my study.

I would like to thanks to my mentor and guide Dr. Karishma Barot for the valuable guidance and advice whenever I needed it.

I would like to thank my participants for their participation, support, and understanding without them it was not easy to carry out the whole research.

\section{Conflict of Interest: None}

\section{Source of Funding: None}

\section{REFERENCES}

1. Canale ST, Cantler ED, Jr., Sisk TD, Freeman BL, 3rd. A chronicle of injuries of an American intercollegiate football team. Am J Sports Med. 1981;9:384-389.

2. Marshall SW, Hamstra-Wright KL, Dick R, Grove KA, Agel J. Descriptive epidemiology of collegiate women's softball injuries: National Col-legiate Athletic Association Injury Surveillance http://dx.doi.org/10.1002/jmri.20783

System, 1988-1989 through 2003-2004. J AthlTrain. 2007;42:286-294.

3. Price RJ, Hawkins RD, Hulse MA, Hodson A. The Football Association medical research pro-gramme: an audit of injuries in academy youth football. Br J Sports Med.
2004;38:466-471.

http://dx.doi.org/10.1136/bjsm.2003.00516

4. Shankar PR, Fields SK, Collins CL, Dick RW, Comstock RD. Epidemiology of high school and collegiate football injuries in the United States, 2005-2006. Am J Sports Med. 2007;35:1295-1303. http://dx.doi.org/ 10.1177/0363546507299745.

5. Bennell KL, Crossley K. Musculoskeletal injuries in track and field: incidence, distribution and risk factors. Aust J Sci Med Sport. 1996;28:69-75.

6. Feeley BT, Kennelly S, Barnes RP, et al. Epidemiology of National Football League training camp injuries from 1998 to 2007. Am J Sports Med. 2008;36:1597-1603. http://dx.doi.org/10.1177/036354650831602 1

7. Hawkins RD, Hulse MA, Wilkinson C, Hodson A, Gibson M. The association football medical re-search programme: an audit of injuries in professional football. $\mathrm{Br}$ J Sports Med. 2001;35:43-47.

8. Askling C, Saartok T, Thorstensson A. Type of acute hamstring strain affects flexibility, strength, and time to return to preinjury level. Br J Sports Med. 2006;40:40-44.

9. Orchard J. Biomechanics of muscle strain injury. N Z J Sports Med.2002;30:92-98

10. Heiderscheit BC, Hoerth DM, Chumanov ES, Swanson SC, Thelen BJ, Thelen DG. Identifying the time of occurrence of a hamstring strain injury during treadmill running: a case study. Clin Biomech (Bristol, Avon). 2005;20:1072-1078.

11. Schache AG, Wrigley TV, Baker R, Pandy MG. Biomechanical response to hamstring muscle strain injury. Gait Posture. 2009;29: 332-338.

12. Chumanov ES, Heiderscheit BC, Thelen DG. The effect of speed and influence of individual muscles on hamstring mechanics during the swing phase of sprinting. J Biomech. 2007;40:3555-3562.

13. THELEN, D., CHUMANOV, E., BEST, T., SWANSON, S. and HEIDERSCHEIT, B., 2005. Simulation of Biceps Femoris Musculotendon Mechanics during the Swing Phase of Sprinting. Medicine \& Science in Sports \& Exercise, 37(11), pp.1931-1938.

14. Yu B, Queen RM, Abbey AN, Liu Y, Moorman CT, Garrett WE. Hamstring muscle kinematics and activation during 
overground sprinting. J Biomech. 2008;41: 3121-3126.

15. Agre JC. Hamstring injuries. Proposed aetiological factors, prevention, and treatment. Sports Med. 1985;2:21-33

16. Clark RA. Hamstring injuries: risk assessment and injury prevention. Ann Acad Med Singapore. 2008;37:341-346.

17. Hennessey L, Watson AW. Flexibility and posture assessment in relation to hamstring injury. Br J Sports Med. 1993;27:243-246

18. Worrell TW. Factors associated with hamstring injuries. An approach to treatment and preventative measures. Sports Med. 1994;17:338-345.

19. Arnason A, Andersen TE, Holme I, Engebretsen L, Bahr R. Prevention of hamstring strains in elite soccer: an intervention study. Scand J Med Sci Sports. 2008; 18:40-48.

20. Croisier JL, Ganteaume S, Binet J, Genty M, Ferret JM. Strength imbalances and prevention of hamstring injury in professional soccer players: a prospective study. Am J Sports Med. 2008;36:14691475.

21. Yeung SS, Suen AM, Yeung EW. A prospective cohort study of hamstring injuries in competitive sprinters: preseason muscle imbalance as a possible risk factor. Br J Sports Med. 2009;43:589-594.

22. Petersen J, Thorborg K, Nielsen MB, et al. Preventive effect of eccentric training on acute hamstring injuries in men's soccer: a cluster-randomized controlled trial. Am J Sports Med 2011;39:2296-303.

23. Opar DA, Williams MD, Shield AJ. Hamstring strain injuries: factors that lead to injury and re-injury. Sports Med 2012;42: 209-26.

24. Lohrer, H., Nauck, T., Korakakis, V. and Malliaropoulos, N., 2016. Validation of the FASH (Functional Assessment Scale for Acute Hamstring Injuries) questionnaire for German-speaking football players. Journal of Orthopaedic Surgery and Research, 11(1).

25. Fleiss, J., 1986. Analysis of data from multiclinic trials. Controlled Clinical Trials, 7(4), pp.267-275.
26. Garrett, W., 1996. Muscle Strain Injuries. The American Journal of Sports Medicine, 24(6_suppl), pp.S2-S8.

27. Woods C, Hawkins RD, Maltby S, et al. The football association medical research programme: an audit of injuries in professional football: analysis of hamstring injuries. Br J Sports Med 2004;38:36-41.

28. Safran MR, Garrett WE, seaber AV, et al. The role of warm up in muscular injury prevention. Am J Sports Med 1988;16:1239.

29. Agre JC. Hamstring injuries. Proposed aetiological factors, prevention, and treatment. Sports Med. 1985;2:21-33.

30. Ali K, Leland JM. Hamstring strains and tears in the athlete. Clinics in sports medicine. 2012;31(2):263-272.

31. Lempainen L, Banke IJ, Johansson K, Brucker PU, Sarimo J, Orava S, et al. Clinical principles in the management of hamstring injuries. Knee surgery, sports traumatology, arthroscopy: official journal of the ESSKA.2015; 23(8):2449-2456.

32. Palmer WE, Kuong SJ, Elmadbouh HM. MR imaging of myotendinous strain. AJR American journal of roentgenology.1999; 173(3):703-709.

33. Askling CM, Tengvar $\mathrm{M}$, Saartok $\mathrm{T}$, Thorstensson A. Acute first-time hamstring strains during slow-speed stretching: clinical, magnetic resonance imaging, and recovery characteristics. The American journal of sports medicine.2007;35(10): 1716-1724.

34. Heiderscheit BC, Sherry MA, Silder A, Chumanov ES, Thelen DG. Hamstring strain injuries: recommendations for diagnosis, rehabilitation, and injury prevention. The Journal of orthopaedic and sports physical therapy.2010;40(2):67-81.

35. Sherry MA, Johnston TS, Heiderscheit BC. Rehabilitation of acute hamstring strain injuries. Clinics in sports medicine.2015;34 (2):263-284.

How to cite this article: Patel K, Barot K. Effect of Nordic hamstring curl exercise to prevent hamstring injury in sprinters. International Journal of Research and Review. 2022; 9(3): 1823. DOI: https://doi.org/ 10.52403/ijrr.20220303 